\section{PROGRAMA PARA LA RESTAURACION DE LOS COLORES DE LOS EDIFICIOS RESIDENCIALES EN EL CASCO URBANO DE ESTOCOLMO}

\section{LOS COLORES DE UN EDIFICIO APORTAN UNA CONTRIBUCION IMPORTANTE AL PAISAJE URBANO}

Nuestro ambiente urbano está constituido por muchos componentes. Entre los más importantes están la arquitectura y la armonización de colores de los edificios. Si echan una mirada a su alrededor observarán cómo afectan al carácter de las calles, de las plazas y de los otros espacios urbanos. La imagen completa depende de lo bien que cada edificio individual puede aportar su contribución.

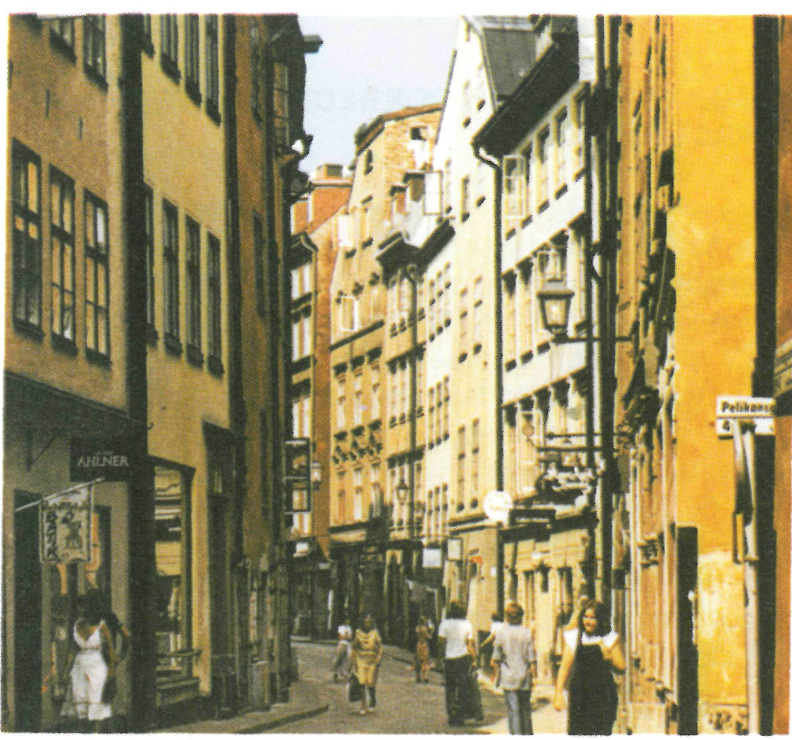

\section{LAS CARACTERISTICAS ORIGINALES DE LOS EDIFICIOS SON IMPORTANTES}

Los edificios que se mantienen en pie en el casco urbano de la ciudad de Estocolmo son parte de una historia viva. Cada uno cuenta su historia de
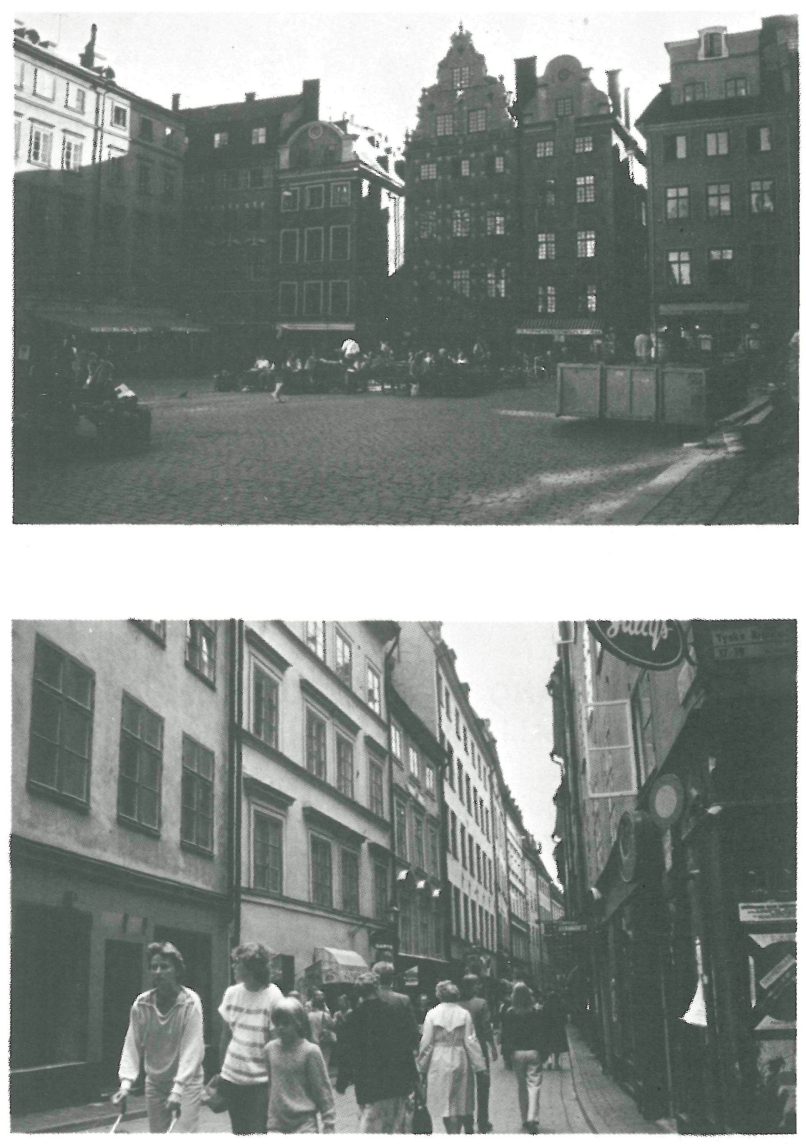

tiempos pasados cuando existían ideales diferentes para los edificios y para la vida en la ciudad.

Los estilos de las distintas épocas de edificación pueden verse claramente en los bloques de la ciudad y sus distritos. Son las marcas del transcurso del tiempo, a semejanza con los anillos indicativos de la edad de los árboles, y como tales proporcionan una belleza especial y un atractivo singular a nuestro entorno. Permitamos que las fachadas de nuestros edificios mantengan su carácter original de modo que cada edificio pueda contribuir a esta saga viviente.

Los edificios del casco urbano no tienen sus características de color por casualidad. Las ordenanzas reales para regular el colorido de los edificios se emitieron muy pronto. A finales del siglo XVII se decidió pintar todas las fachadas con un matiz amarillento para dar más claridad a las calles. Más adelante, las normas para colorear los edificios se dieron en ordenanzas especiales para la construcción, que todavía eran aplicables en Estocolmo a principios de nuestro siglo. Ha sido un esfuerzo constante por encontrar colores pálidos, aunque el blanco puro se considerara inadecuado. 


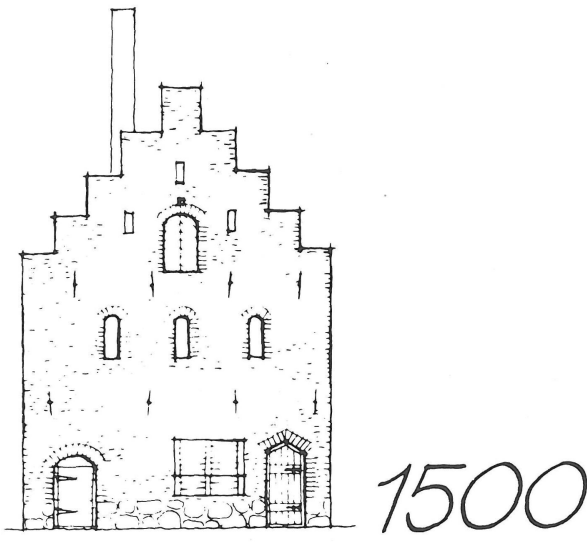

\section{EL CASCO URBANO DE ESTOCOLMO: UN ENTORNO VALIOSO}

Las exigencias que pueden hacerse sobre el diseño de nuestro paisaje urbano se establecen en el Código de la Construcción. En la primer cláusula se dice:

"La fachada exterior de un edificio deberá diseñarse y colorearse de acuerdo con las exigencias planteadas por el entorno paisajístico, para obtener un conjunto armonioso y para proporcionar un efecto total atractivo. Asimismo, dentro de cualquier zona urbanizada que comprenda un entorno valioso, habrá de prestarse especial atención al carácter distintivo de esa área.»

Lo anterior implica que:

* La parte subrayada del texto se refiere a una zona específica cuando se ha definido como tal por una decisión municipal pertinente.

* Los moradores de dichas zonas valiosas deberán proveerse con una información clara por parte del municipio. En este informe habrá de indicarse claramente los valores perdurables que contienen y qué puede hacerse para su restauración y su conservación. De este modo, con anterioridad, el individuo estará capacitado para realizar la integración de las prescripciones sobre la conservación con sus propias ideas y sus propios deseos.

El casco urbano de Estocolmo incluye el tipo de entorno valioso y bien integrado hacia el que está dirigida esta legislación. Así, el 13 de noviembre de 1980, la Comisión de Urbanismo de Estocolmo decidió deslindar el casco urbano de Estocolmo como una zona valiosa, de conformidad con el Código de la Construcción.
Este programa ambiental se refiere a la coloración de los edificios existentes dentro de la zona deslindada. La concepción del programa se basa en el proyecto de ley que el gobierno sueco presentó al parlamento.

De conformidad también con el Código de la Construcción, los edificios que tengan un valor cultural histórico no pueden ser objeto de modificaciones indebidas. Para el casco antiguo, en su integridad, esto se estipula en el Plan Estatutario Municipal.

\section{COMO INTERPRETAR CORRECTAMENTE EL PROGRAMA}

Por "características de color" se quiere significar las más importantes en la composición de colores asociada con una época concreta y un estilo de edificación particular. Dichas características están relacionadas con el diseño de la fachada como un conjunto, sus detalles decorativos, su composición y sus materiales. En las fachadas ricamente esculpidas del edificio típico de la década de los años $80 \mathrm{del}$ siglo pasado, por ejemplo, las características del color consistian en yeso con coloración pálida, en imitación de piedra arenisca. Por el contrario, las características de color de los edificios escasamente decorados de los años 20 de nuestro siglo se consiguen mediante un contraste armonioso de acabados de yeso vivamente coloreados en rojo o verde. No se puede transferir las caracteristicas de color desde un período a otro. Por ejemplo, sería incorrecto colorear un edificio de la década de 1880 en rojo o verde.

Este programa concretado en un poster, pone de manifiesto las características de color más importantes de aquellos edificios que son caracteristi- 

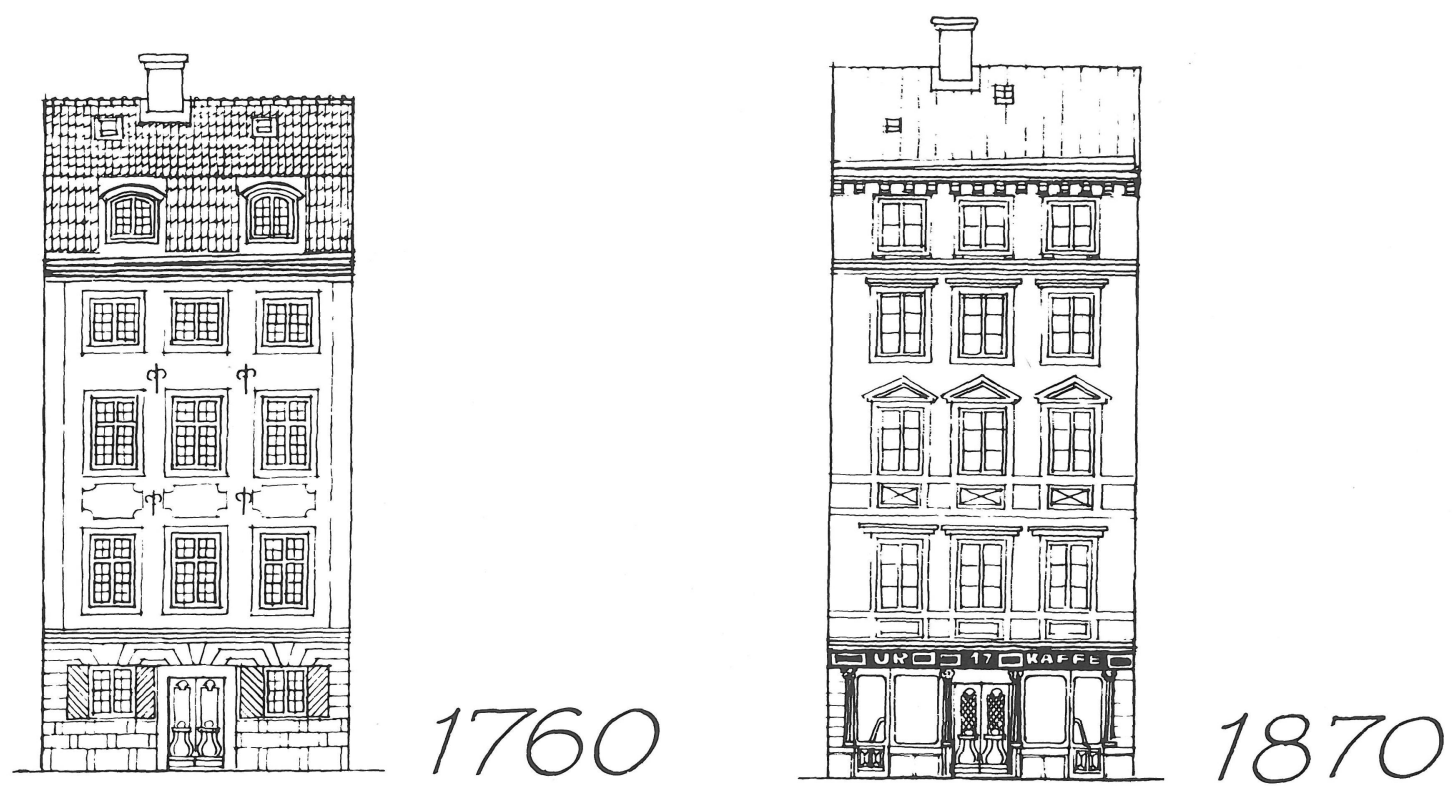

cos de los distintos períodos durante los cuales se desarrolló el casco urbano. Están ilustrados por cinco hileras coloreadas de fachadas de edificios, una por cada década durante los cincuenta años entre 1880 y 1930. La gran mayoría de los edificios residenciales del casco urbano se construyeron durante ese periodo. Relacionada con cada hilera de fachadas hay una breve descripción del diseño y las caracteristicas de color típicas de cada década. Así se puede conseguir una impresión del estilo de edificación y de las características de color de cada época. En realidad, en el ámbito de una calle pueden existir, por supuesto, varios edificios de diferentes décadas.

A través de este programa, el casco urbano se ha deslindado como una zona especialmente valiosa. La especial atención que debe prestarse, en la selección de los colores adecuados para los edificios residenciales, se pone de manifiesto ilustrando qué caracteristicas de color son típicas de cada época.

\section{ELECCION DE COLORES}

Averiguando cuándo se construyó el edificio y cuál es la fachada que le corresponde, y con la ayuda de las hileras de fachadas en el poster, es fácil determinar qué características de color son adecuadas para cada edificio particular. La elección de los matices cromáticos correspondientes puede basarse en las características de color. Una amplia gama de matices y tonalidades se adaptan a cada característica de color. El Grupo Consultor sobre Colores, en la Oficina de Planificación Municipal, proporciona recomendaciones adicionales sobre qué colores elegir.

Es dificil elegir una matiz sobre la base de pequeñas muestras de colores, puesto que un color se experimenta como más intenso cuando se pinta sobre una superficie grande. Las hileras de fachadas en el poster ilustran cómo aparecen los colores cuando se ven desde una cierta distancia. Así, no se puede elegir un matiz cromático colocando una muestra del color sobre las hileras impresas de fachadas en el poster. Si, por el contrario, encontrara un edificio real pintado en los colores adecuados, puede comparar muestras de colores próximas a la superficie de la fachada, con el fin de poder determinar la elección de colores.

\section{ESTILOS ARQUITECTONICOS Y CARACTERISTICAS DE COLOR EN EL PERIODO DE 1880 A 1930}

\section{Década de 1880}

Las fachadas de esta década estaban simétricamente diseñadas. Las ventanas son equidistantes. Los dos pisos más bajos suelen ser de un relieve de yeso en imitación de piedra. Las bandas alrededor de las ventanas del tercer piso están diseñadas de una forma muy notoria. Pilastras de dos pisos suelen enlazar este piso con el situado inmediatamente encima. Una rica armonía de sombra se consigue mediante unas molduras de perfil vertical y horizontal entre cada piso, por debajo del techo y alrededor de las ventanas, en combinación frecuente con ornamentación de yeso moldeado.

Los colores de las fachadas están concebidos para imitar a la piedra de arenisca amarilla. Son comunes las imitaciones pálidas con tonos de piedra de colores pardo amarillento, amarillo parduzco y blanco grisáceo. El yeso tiene un acabado suave. Los frisos y las decoraciones tienen los mismos colores que la fachada. La base es del 
mismo color que la fachada o tiene una tonalidad grisácea más profunda, imitando a la piedra.

La carpintería de madera es de color castaño, marrón oscuro, castaño rojizo o gris verdoso oscuro. Las jambas de las ventanas suelen ser de perfil transversal. La puerta de entrada está pintada en el mismo color que las ventanas o en una tonalidad más oscura.

Los tejados están constituidos por entablado metálico negro con juntas de solapamiento.

\section{Década de 1890}

Las características más notables de los edificios de esta década son las siluetas imaginativas de los tejados. Los edificios de esquina tienen torretas o aleros con piñones, que se suelen adornar con tracería de fundición para reforzar una ilusión de altura. Una nueva búsqueda de materiales genuinos condujo a la construcción de muchos de los edificios de mayor coste en piedra natural, tal como piedra de arenisca rojiza o amarillenta o piedra caliza de color blanco grisáceo. Son frecuentes los ladrillos rojos en fachadas, que suelen estar en combinación con piedra de arenisca, piedra caliza o con un acabado amarillo grisáceo a imitación de piedra. La hilera de fachadas ilustra cuatro variedades de ladrillo de fachada con esta combinación. Las fachadas de muros enlucidos suelen combinar secciones con un revestimiento esparcido en basto con otras secciones de acabado suave en el mismo color.

Los colores de las fachadas son amarillo pálido ocre, rosa parduzco pálido, gris o blanco amarillento; todos ellos colores que se combinan bien con la piedra natural. En las paredes están montados rellenos de elementos cerámicos: azulejos, ladrillos vidriados y murales incrustados. Hierros de anclaje, imaginativamente forjados y pintados de negro, suelen ser visibles en la fachada.

La carpinteria de madera es de color marrón oscuro, gris verdoso oscuro, gris cálido (con matices amarillo-rojizos) o está manchada bajo un barniz. Las ventanas suelen tener arcos con jambas centrales en forma de $T$. Las formas y el espaciamiento de las ventanas varian y están relacionadas con el diseño total del edificio. La obra de sillería de los arcos por encima de las ventanas contrasta notablemente con la fachada. Las puertas de entrada están barnizadas en tonalidad marrón o simplemente barnizadas. Los pórticos están claramente destacados del resto de la fachada, elevándose con frecuencia en varios pisos.

Los tejados están instalados con un entablado negro liso con juntas de solapamiento.

\section{Década de 1900}

A principios de siglo se introdujo el "Art Nouveau". Las fachadas se enlucieron con yeso y suelen tener columnas suavemente salientes de miradores que se elevan por encima de las cornisas. El acabado de yeso es liso y está adornado mediante líneas rectas finas, decoración foliar en relieve y, a veces, con hileras de azulejos brillantes. La base es de piedra caliza o de piedra de arenisca, embellecida alrededor de la entrada, que suele estar arqueada.

Los colores de las fachadas son claros y brillantes. Los colores amarillo, amarillo rojizo y rosa amarillento pálido son muy comunes, pero no son raros los colores rosa pálido y blanco amarillento. Los contornos moldeados, las secciones de yeso esparcido en basto $y$ otros elementos ornamentales siempre tienen el mismo color que el resto de la fachada.

La carpintería de madera es de color rojo inglés, verde oliva y verde óxido, pero también se utilizan las coloraciones gris verdosa y pardo claro. Las partes superiores de las ventanas tienen cuarterones pequeños. Las puertas de entrada están barnizadas sobre un fondo coloreado o simplemente barnizadas. Los tejados de los edificios más sencillos están provistos de un revestimiento con juntas de solapamiento, pintado de color rojo o verde. Los edificios de más alto coste tienen tejados de tipo chalet de revestimiento verde cobre o de losetas vidriadas.

\section{Década de 1910}

Esta década está inmersa en el estilo romántico nacional, con fachadas cerradas pesadas y tejados de fuerte inclinación. Cuando las columnas de miradores sobresalen por encima de la cornisa, tienen sus propios tejados. Bloques de granito toscamente desbastados se utilizan para la base, que puede estar diseñada, con frecuencia, para compensar las considerables diferencias en el nivel de las calles en pendiente. Obras de sillería artísticamente esculpidas suelen destacar las entradas. Algunas fachadas son de ladrillo pardo rojizo con una ornamentación bien definida.

Otras paredes están pintadas al temple y acabadas en basto. Un estuco de alta calidad del mismo color que la piedra de la base se suele utilizar en fachadas enlucidas. Piedra machacada, tal como mármol, azulejos, ladrillos o granito, se utilizan para dar al estuco el color de la piedra.

Los colores de las fachadas están así limitados a las tonalidades más oscuras y más claras de los colores marrón, rosa parduzco, pardo claro y blanco grisáceo. Las ventanas con pequeños cuarterones, a ras con la fachada, refuerzan la impresión. 
La carpintería de madera en los edificios de color ladrillo es de color marrón o blanco. Las fachadas con revestimiento claro tienen carpintería de madera blanca. Las puertas de entrada suelen ser de roble barnizado.

Los tejados están instalados con tejas cóncavas, - flamencas, de color rojo o con tejas vidriadas oscuras en color verde, rojo o negro. Las buhardiIlas del piso superior suelen estar revestidas de cobre.

\section{Década de 1920}

Las fachadas suavemente enlucidas de esta década están decoradas con frisos, pilastras, medallones y otros motivos de la arquitectura clásica. También se encuentran obras salientes en cobre. Los edificios son más compactos; los pisos se construyen con menor separación. Grandes pórticos abovedados conducen a los patios de vecindad. Las ventanas están a ras con la fachada frontal. Es muy frecuente utilizar una lechada de cal espesa para dar una superficie atractiva a la fachada. También se encuentran fachadas de paredes pintadas al temple y con estuco coloreado. Los colores elegidos están en armonia con el aspecto de las fachadas.

Los colores de las fachadas son oscuros y completos: rojo oscuro, amarillo parduzco, pardo rojizo, amarillo ocre y rojo amarillento. También se encuentran los colores pardo claro, rosa grisáceo y verde. Los frisos y los elementos decorativos tienen un color pardo claro imitación de piedra en contraste con el color de la fachada. El yeso en la base suele ser estuco impregnado de gris grafito, aparentando piedra artificial.

La carpintería de madera está pintada con colores verde oscuro, gris verdoso, gris azulado, gris, pardo rojizo, ocre, gris claro o blanco sucio (mate).
Las ventanas son más pequeñas que en periodos anteriores y están constituidas por seis cuarterones de cristal del mismo tamaño.

Los tejados son bajos y constituidos con planchas provistas de juntas de solapamiento rojas o negras $y$, a veces, con tejas o pizarras.

\section{EL POSTER DE COLORES}

Este poster de colores está actualmente muy difundido $y$ es bien conocido en Estocolmo y en toda Suecia en general. Pero es algo más que una atractiva ilustración de las fachadas. También se trata de un programa de restauración municipal relativo a los colores de las fachadas en las zonas centrales de Estocolmo y está basado en una decisión política. Este programa confirma una tendencia general y un cambio de actitud hacia los edificios residenciales más antiguos todavia existentes. Se ha elaborado como un elemento en una serie de programas ambientales para la restauración y el nuevo desarrollo en el Municipio de Estocolmo. Asimismo, está basado en un nuevo tipo de legislación. En el mes de julio de 1980 se hizo una adición de gran importancia al Código Sueco de la Construcción. Dicha adición permite a los municipios establecer las zonas construidas de un interés especial por una simple decisión municipal. Dentro de dichas zonas debe prestarse especial atención a su carácter distintivo. El Municipio está obligado también a informar a los habitantes de los valores especiales incluidos en esa zona y la forma en que han de restaurarse y conservarse. La Comisión de Urbanismo Municipal de Estocolmo decidió, asi, el 13 de noviembre de 1980, considerar al casco urbano antiguo de Estocolmo como una zona valiosa. Los valores especiales que se definieron en relación con dicha decisión se refieren a la restauración de colores de las fachadas del casco urbano. 